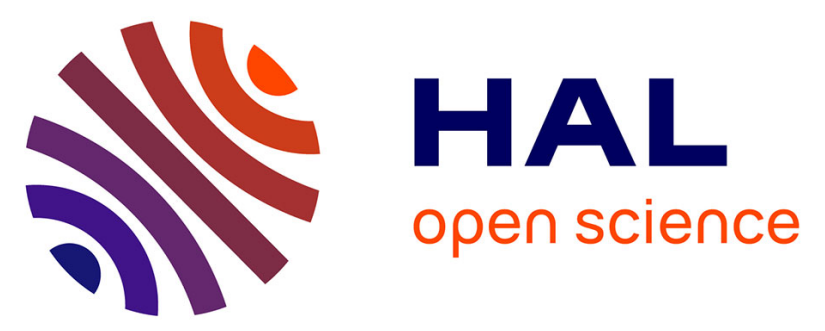

\title{
Detailed Investigation of Compatibility of Hydrothermal Liquefaction Derived Biocrude Oil with Fossil Fuel for Corefining to Drop-in Biofuels through Structural and Compositional Analysis
}

\author{
K. Sharma, T. Pedersen, S. Toor, Y. Schuurman, L. Rosendahl
}

\section{To cite this version:}

K. Sharma, T. Pedersen, S. Toor, Y. Schuurman, L. Rosendahl. Detailed Investigation of Compatibility of Hydrothermal Liquefaction Derived Biocrude Oil with Fossil Fuel for Corefining to Drop-in Biofuels through Structural and Compositional Analysis. ACS Sustainable Chemistry \& Engineering, 2020, 8 (22), pp.8111-8123. 10.1021/acssuschemeng.9b06253 . hal-02903027

\section{HAL Id: hal-02903027 \\ https://hal.science/hal-02903027}

Submitted on 2 Mar 2021

HAL is a multi-disciplinary open access archive for the deposit and dissemination of scientific research documents, whether they are published or not. The documents may come from teaching and research institutions in France or abroad, or from public or private research centers.
L'archive ouverte pluridisciplinaire $\mathbf{H A L}$, est destinée au dépôt et à la diffusion de documents scientifiques de niveau recherche, publiés ou non, émanant des établissements d'enseignement et de recherche français ou étrangers, des laboratoires publics ou privés. 


\title{
Detailed Investigation of Compatibility of Hydrothermal Liquefaction Derived Biocrude Oil with Fossil Fuel for Corefining to Drop-in Biofuels through Structural and Compositional Analysis
}

\author{
Kamaldeep Sharma, Thomas Helmer Pedersen, Saqib Sohail Toor, Yves Schuurman, \\ and Lasse Aistrup Rosendahl*
}

\begin{abstract}
Large-scale commercialization of drop-in biofuel technologies requires a deeper understanding of the molecular structure of biocrude oils and their compatibility with fossil crudes in terms of molecular interactions that govern miscibility. For the first time, the compatibility of hydrothermal liquefaction (HTL) derived biocrude obtained from pinewood with straight-run gas oil (SRGO) was comprehensively investigated by theoretical prediction using Hansen double sphere plots and experimental confirmation from miscibility studies to achieve a biofeed compatible for coprocessing at refineries. The Hansen solubility parameters (HSPs) for biocrude, biocrude components (residue and light and heavy distillate fractions), and SRGO were determined by plotting a three-dimensional Hansen solubility sphere plot based on the experimental solubility data obtained on their solubility studies in 38 different solvents. The compatibility of HTL biocrude oil with SRGO was verified from the solubility distance $\left(R_{a}\right)$ and relative energy difference (RED) values obtained from the center of their Hansen spheres and difference in HSPs, respectively, in a Hansen double sphere solubility plot. The experimental data obtained on miscibility studies confirmed that pyridine, cyclohexanone, and a pyridine-cyclohexanone solvent mixture (1:1) occupy a well-defined Hansen space and show fitting to HSPs of the biocrude-SRGO blend, improve the overall compatibility of the blending mixture, and display a maximum miscibility of $72 \%$. To correlate the compatibility with the molecular structure, the compatibility of light, heavy, and residual fractions obtained by fractional distillation of HTL biocrude (pinewood) was also evaluated with SRGO using the Hansen double sphere plot, and a close agreement with differential scanning calorimetry (DSC) results as well as the experimental data on miscibility studies was verified. Furthermore, the comprehensive estimation of the detailed composition and chemical nature of biocrude and light, heavy, and residual fractions by the means of elemental $(\mathrm{CHN} / \mathrm{O})$, GC-MS, and GC $\times$ GC analysis was also presented. Additionally, the correlation between compatibility and interactions within chemical functionalities of blend components was established by analyzing the contribution of aromatic, aliphatic, and oxygen containing functional groups to the miscibility using quantitative 13C NMR spectroscopy. The present study reports a mixing strategy to assess the compatibility of biocrudes, heavy distillate fractions, asphaltenes, residues, and polymers with existing petroleum infrastructure for the cost-effective biorefinery process to balance economic and environmental considerations.
\end{abstract}

KEYWORDS: Hydrothermal liquefaction, Biocrude, Compatibility, Fossil fuel, Corefining, Drop-in biofuels

\section{INTRODUCTION}

There is considerable interest in developing drop-in biofuels as alternative liquid fuels for the renewable replacement of petroleum, particularly in aviation and heavy transport sectors where there is no real substitute to sustainably produced biofuels. ${ }^{1}$ Although the technology used for the production of transport fuel from crude oil is well established, the environmental (e.g., $\mathrm{CO}_{2}$ and active sulfur species) and sustainability issues of these fuels have prompted growing interest in the development of biofuels from biorenewable feedstocks. ${ }^{2}$ Alternative biofuels obtained from biomass feedstock are strong candidates to reduce the environmental impact of aviation exerted during the fuel burning by providing a solution to the current energy and climate problems. ${ }^{3}$ Hydrothermal liquefaction (HTL) is considered a very promising technology for the conversion of wet biomass into sustainable biocrude oils with low oxygen contents as 
alternative feedstocks for the production of liquid fuels. ${ }^{4}$ As a wet processing technology, HTL is generally carried out in aqueous media of at least $50 \%-60 \%$ water, around $250-450$ ${ }^{\circ} \mathrm{C}$ temperature, and pressures between 10 and $30 \mathrm{MPa}$, making it very suitable for most natural biomasses and organic residues. ${ }^{5}$ Furthermore, the HTL process offers high conversion rates, flexibility with regard to different feedstocks, and catalytic effect of the reaction medium. ${ }^{5}$ Comparatively, HTL biocrudes are more stable fuels with high heating value, low oxygen contents, gases, and volatile matters than pyrolysis oils. ${ }^{6}$ Although HTL biocrudes with improved fuel properties produced directly from wet biomass feedstocks are attractive from both a fuel market and infrastructure perspective, these biocrudes are not fully compatible with the overall petroleum fuel refining or the existing liquid transportation fuel processing equipment because of high viscosity, large fraction of heavy residue, and heteroatom contents. ${ }^{7,8}$ Therefore, processing of HTL biocrudes in order to improve their chemical and physical properties is a prerequisite to produce drop-in biofuels fully compatible with existing fossil streams for coprocessing in the conventional petroleum refinery. Previously, the upgrading of HTL biocrudes to drop-in biofuels has been extensively studied using the hydrotreating or catalytic upgrading techniques. $^{9-11}$ Compared with the above techniques, the direct use of HTL biocrudes accomplished by blending with fossil streams at a low concentration is potentially an economically feasible drop-in point. ${ }^{12}$ Alternatively, as compared to conventional fuels, the finished fuel prepared by blending HTL bio-oil extract with diesel fuel significantly reduces particulate number and particulate matter without affecting the engine performance. ${ }^{13}$ A primary requirement for the conversion of biocrudes to a readily usable biofuel blend is the production of material blends with fuel characteristics comparable to the existing gasoline and diesel standards (ASTM) so that conventional petroleum infrastructures can be implemented. Therefore, methods are required that can efficiently predict the compatibility of biocrude oils with the fossil fuels on the basis of their solubility characteristics for the economic conversion to dropin transportation fuels. In this aspect, a deep understanding of the solubility characteristics and molecular components of HTL biocrude oils is required to ensure the solubility of individual components and the mutual miscibility of constituents in material blends with fossil refinery streams. Solubility parameters as a basic physicochemical property have played a significant role in defining the solubility characteristics and the screening of solvents or materials compatible for a substance. ${ }^{14-16}$ However, there are only a few reports in the literature regarding the use of solubility parameters for the prediction of solubility of crude oils and bitumen in different solvents. ${ }^{17,18}$ The Hansen solubility parameter (HSP) approach has proven itself to be a valuable predictor of solubility based on solubility parameters of different materials such as polymers, ${ }^{19}$ adhesives, ${ }^{20}$ organic compounds, ${ }^{21}$ graphene derivatives, ${ }^{22}$ carbon nanotubes (CNTs), ${ }^{23}$ medicinal compounds, ${ }^{24}$ asphaltenes, ${ }^{25}$ ionic liquids, ${ }^{26}$ and organogels ${ }^{27}$ in different solvents. Yamamoto et al. ${ }^{26}$ used the Hansen double sphere method and calculated the HSPs of ionic liquids based on the Hansen solubility approach. The resulting HSPs were used to represent the domain structure and compatibility index of ionic liquids. These reports show that the solubility/ compatibility of different substances can be easily visualized from the Hansen sphere plot using their HSPs. Recently, we have investigated the solubility behavior of renewable HTL bioliquids and refinery streams using the solubility parameters. $^{28}$ To the best of our knowledge, there is no report in the literature regarding the use of the Hansen double sphere approach for the prediction of compatibility of HTL biocrudes and their components with petroleum refinery streams or fuels. For the first time, the compatibility of HTL biocrude with fossil fuel has been investigated comprehensively by both theoretical predictions and experimental analysis to achieve a biofeed suitable for coprocessing in petroleum refineries. The aim of the present study is therefore to identify the common range of solubility parameters for the deep understanding of solubility characteristics of HTL biocrude and to establish a correlation between miscibility and molecular structure of biocrude to assess its compatibility with refinery streams. It is therefore essential to determine the most appropriate insertion points for HTL biocrude into the conventional petroleum infrastructure for coprocessing. Figure 1 reveals the insertion

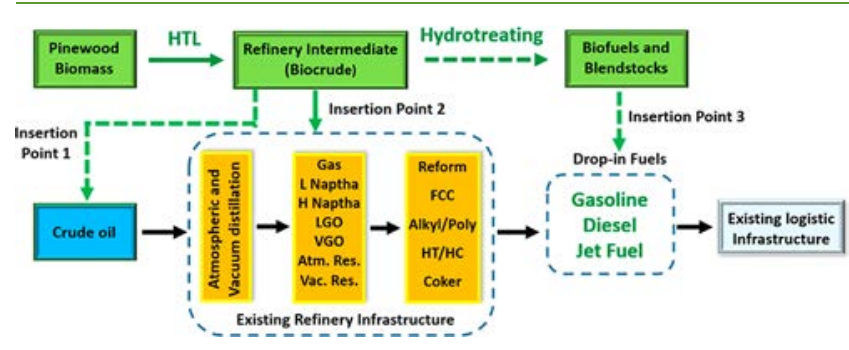

Figure 1. Insertion points for HTL biocrude to integrate into existing petroleum refineries and distribution infrastructure.

points for HTL biocrude at different stages to integrate into existing petroleum refineries and distribution infrastructure. The test liquid employed for the miscibility of HTL biocrude is straight-run gas oil (SRGO), a dominant precursor for diesel production, obtained by atmospheric distillation of natural crude oil. ${ }^{29}$ As previously reported, the coprocessing of bio-oil with SRGO leads to the production of an oil rich in diesel fractions. $^{30}$

In the present manuscript, the HSPs of HTL biocrude from pinewood and SRGO were determined from the experimental data obtained on solubility studies in 38 different solvents, which were used to evaluate their extent of compatibility by plotting the Hansen double sphere plot (Figure 2a). Relative energy difference (RED) and $R_{\mathrm{a}}$ parameters calculated from the two Hansen solubility spheres of biocrude and SRGO explain the interaction potential and difference in affinity tolerable for the complete mixing of HTL biocrude and SRGO. To amplify the miscibility of the biocrude-SRGO blend, the solvents that occupy a well-defined space with less distance from the junction of the biocrude-SRGO mixture in the Hansen space were selected, and a close agreement with the experimental data from miscibility studies was verified. Furthermore, the HTL biocrude was fractionated into light, heavy, and residual subfractions through the fractional distillation; the compatibility of these individual fractions with SRGO was also determined by both the Hansen double sphere approach and miscibility studies. The complete miscibility of the blends of light, heavy, and residual fractions with SRGO was also indicated from DSC curves and spot tests. The qualitative identification of individual chemical compounds present in all the samples was also achieved by elemental analysis (CHN/O), GC-MS, and GC $\times$ GC-MS 

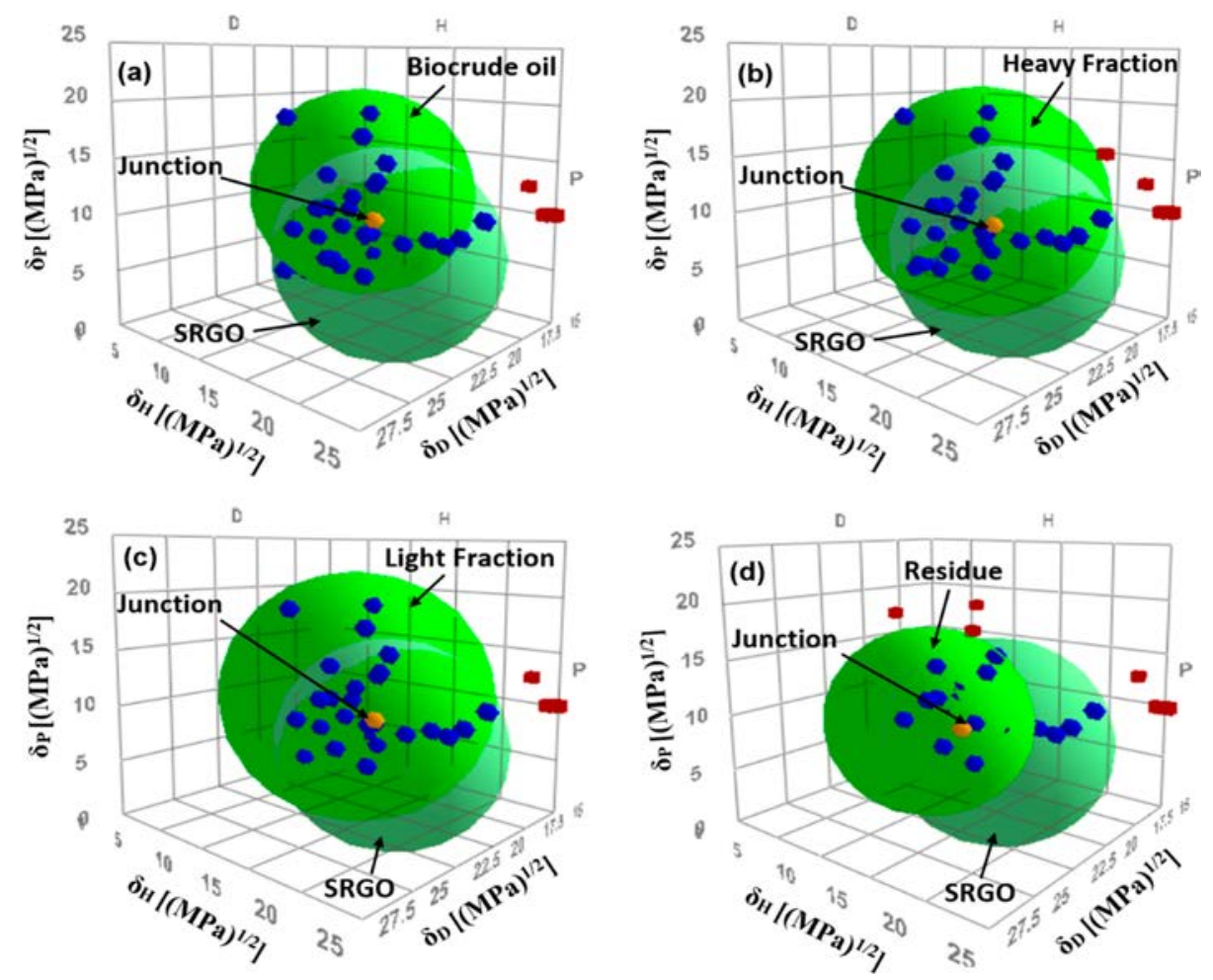

Figure 2. Hansen double sphere plot showing the compatibility of (a) HTL biocrude, (b) heavy fraction, (c) light fraction, and (d) residue with SRGO.

Table 1. Calculated HSPs for Selected Derivatives and Solvents from Solubility Studies Results

\begin{tabular}{|c|c|c|c|c|c|c|c|c|}
\hline sample & $\delta_{\mathrm{D}}$ & $\delta_{\mathrm{P}}$ & $\delta_{\mathrm{H}}$ & $\delta$ & $R_{0}$ & fit & wrong in & wrong out \\
\hline biocrude & 17.44 & 10.67 & 8.58 & 21.90 & 10.2 & 0.982 & 1 & 1 \\
\hline heavy fraction & 16.81 & 9.13 & 7.90 & 21.3 & 11.9 & 1.000 & 0 & 0 \\
\hline light fraction & 18.77 & 9.92 & 9.81 & 21.9 & 12.0 & 0.971 & 1 & 0 \\
\hline residue & 20.51 & 8.03 & 8.64 & 23.7 & 9.1 & 0.914 & 1 & 2 \\
\hline SRGO & 16.22 & 3.98 & 9.76 & 18.1 & 11.0 & 0.934 & 1 & 2 \\
\hline pyridine & 19 & 8.8 & 5.9 & & & & & \\
\hline cyclohexanone & 17.8 & 8.4 & 5.1 & & & & & \\
\hline pyridine-cyclohexanone (50\%) & 18.4 & 8.6 & 5.5 & & & & & \\
\hline
\end{tabular}

techniques. We envisioned that the evaluation of interactions between the bio-oil components could provide additional information regarding the molecular structure and the determination of the properties of the blends. Therefore, the effect of the molecular structure of the biocrude, subfractions, and residue on the compatibility are estimated quantitatively by analyzing the contribution of aliphatic, aromatics, and oxygen containing functional groups for miscibility using ${ }^{13} \mathrm{C}$ NMR spectroscopy. Consequently, the correlations between component interactions and the miscibility as well as between structure and physicochemical properties are established. This study offers a straightforward and flexible approach for estimating the physicochemical properties of biocrudes and light, heavy, and residual subfractions based on the solubility characteristics to optimize their commercial value, and analysis of the solubility parameters may provide a better understanding of the molecular interactions that control miscibility.

\section{RESULTS AND DISCUSSION}

Solubility studies of HTL biocrude obtained from pinewood in SRGO were carried out experimentally in 38 different solvents according to the previously reported procedure. ${ }^{31}$ The data obtained from the solubility studies of biocrude and SRGO were fitted using the HSPiP software (Fit $=0.982$ and 0.934). HSPs for the biocrudes and SRGO were calculated by plotting a 3D Hansen solubility single sphere plot based on the solubility data (Table 1 ). The resulting HSPs were used to predict the compatibility of HTL biocrude with SRGO via the Hansen double sphere solubility approach, which was verified with the experimental results of miscibility studies. Figure $2 \mathrm{a}$ shows the 3D Hansen double sphere plot for the biocrudeSRGO blend with the set of all 38 solvents.

The blue points are good solvents and lie inside the two solubility spheres, whereas the red points reside outside the spheres evaluated as bad solvents for the biocrude-SRGO blend. In the Hansen double sphere plot, the solubility sphere with high $\delta_{\mathrm{P}}$ value is the biocrude (more polar) as shown in Table 1 , and the one with the low $\delta_{\mathrm{P}}$ value is SRGO (less polar). The yellow point between two spheres is the junction value "sweet spot" that defines the solvents most likely to interact with the blending mixture. Generally, the volume of the area of overlap between the two solubility spheres provides the actual information on the compatibility of two substances. $^{32}$ The larger the area of overlap between two 
spheres, the more the compatibility between them. The Hansen double sphere plot for the biocrude-SRGO blend shows weak overlap between the two spheres, which indicates the poor compatibility of HTL biocrude with SRGO (Figure 2a).

Furthermore, the experimental solubility parameters such as RED and $R_{\mathrm{a}}$ were also calculated for the biocrude-SRGO blend (eqs 2 and 3) which provide the relative energy difference between biocrude and the SRGO as well as the difference in their HSPs, respectively. The higher the value of these solubility parameters, the lower the compatibility. The results mentioned in Table 2 show the high RED and $R_{\mathrm{a}}$ values

Table 2. Calculated HSPs, RED, and $R_{\mathrm{a}}$ Values for Selected Blending Mixtures from Miscibility Study Results the Using Hansen Double Sphere $\operatorname{Plot}^{a}$

\begin{tabular}{lccccc}
\multicolumn{1}{c}{ blends } & $D_{\mathrm{j}}$ & $P_{\mathrm{j}}$ & $H_{\mathrm{j}}$ & $\mathrm{RED}$ & $\begin{array}{c}\text { distance } \\
\left(R_{\mathrm{a}}\right)\end{array}$ \\
$\begin{array}{l}\text { pinewood biocrude- } \\
\quad\end{array}$ & 17.60 & 5.60 & 6.20 & 0.607 & 6.25 \\
$\begin{array}{l}\text { heavg fraction-SRGO } \\
\text { light fraction-SRGO }\end{array}$ & 16.70 & 6.30 & 9.40 & 0.359 & 4.74 \\
residue-SRGO & 16.70 & 6.80 & 9.60 & 0.465 & 5.86 \\
& 18.60 & 6.10 & 8.60 & 0.935 & 8.51
\end{tabular}

${ }^{a} D_{\mathrm{j}}, P_{\mathrm{j}}$ and $H_{\mathrm{j}}$ are the HSPs for the junction of the selected blending mixtures.

of the biocrude-SRGO blend, which again confirm the poor compatibility of HTL biocrude with SRGO. The miscibility of HTL biocrude in SRGO was also checked by using the procedure as mentioned in the Experimental Section. For this, different proportions of biocrude (1-5 wt \%) were mixed in SRGO (95-99 wt \%) thoroughly using the vortex mixer for 15 min. The results showed that the HTL biocrude is immiscible in SRGO, which corroborates the theoretically predicted low values of compatibility. These studies show that the compatibility of HTL biocrude predicted from HSPs based on the solubility characteristics are most precise when comparing to those of solution-blended systems.

To amplify the compatibility of HTL biocrude in SRGO, we made a preliminary prediction using the Hansen double sphere approach to determine new solvents compatible with the biocrude-SRGO blend. Generally, solvents that lie within or close to the overlap (junction) of the two-solubility sphere aid the compatibility of the system. Consequently, the solvents occupy a well-defined region in solubility space, and those having a short solubility distance from the junction of the biocrude-SRGO blend were selected. Figure 3A shows a range of good solvents lying close to the junction of the biocrudeSRGO blend. The solvent affinity was also measured in a group of solvents by mixing them in different proportions with biocrude-SRGO blend using the vortex mixer (Table 3). After that, the blending mixture was filtered by vacuum filtration to determine the amount of immiscible residue present in the blend. The results of the miscibility studies displayed a miscibility of 62 and $65 \%$ of biocrude in SRGO in the presence of pyridine and cyclohexanone solvents, respectively (Table 3 ). Based on miscibility studies with pure solvents to enhance the compatibility, solvent mixtures with HSPs fitting with that of biocrude were determined and tested as dispersing agents for the biocrude-SRGO blend. Furthermore, the solvent mixtures such as pyridine-cyclohexanone and pyridine-2-heptanone were also employed to achieve the complete miscibility of

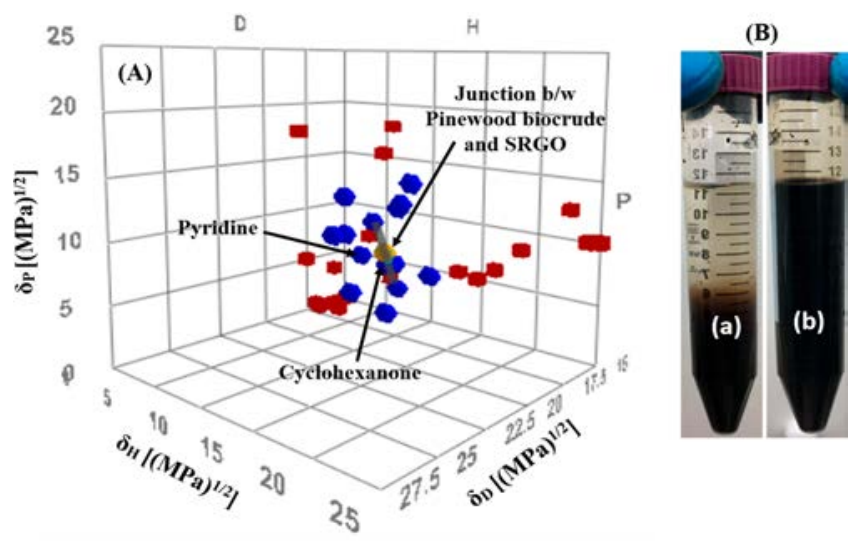

Figure 3. (A) Hansen solubility map showing the affinity of different solvents for the biocrude-SRGO mixture (50:50) in terms of their polarities. (B) Visual inspection of the biocrude-SRGO blend (a) without cosolvent and (b) in the presence of pyridine-cyclohexanone as cosolvent.

HTL biocrude in SRGO (Table 3). The best solvent mixture was pyridine-2-heptanone, which displayed a maximum miscibility of $74 \%$; however, $72 \%$ miscibility of biocrude was observed in the presence of the pyridine-cyclohexanone solvent mixture. Figure $3 \mathrm{~B}$ shows the visual evaluation of miscibility of the biocrude-SRGO blend in the presence of the pyridine-cyclohexanone solvent mixture that demonstrates the affinity of this solvent mixture in significant improvement of the miscibility of biocrude in SRGO. These results are consistent with the theoretical predictions of the solvent affinity for the biocrude-SRGO blend made by using solubility parameters. Thus, the Hansen solubility approach does not only predict the solubility parameters of materials but also predicts the affinities of different solvents to improve their compatibilities in blends.

To get insight into the reason for incompatibility and role of structural components in miscibility, HTL biocrude was fractionated into subfractions from which extensive characterization experiments may impart further information on the contribution of different functional groups and molecular interactions to the compatibility. The fractional distillation of HTL biocrude was carried out in accordance to ASTM D2892 in a two liter 15:5 distillation column as mentioned in the literature. ${ }^{33}$ Prior to distillation, the biocrude was dehydrated at the atmospheric equivalent temperature (AET) of $130{ }^{\circ} \mathrm{C}$ through vacuum distillation in a stand-alone setup. To avoid thermal cracking of biocrude, the distillation procedure was divided into several steps according to the processing conditions. Initially, the distillation was performed at atmospheric pressure; hereafter, the distillation was continued under vacuum until an end point of approximately $370{ }^{\circ} \mathrm{C}$ AET. The distillates were divided into 8 liquid fractions and a distillation residue (Figure 4). The distillation residual fraction defines the bulk of the nonvolatile compounds having boiling points above $\sim 370{ }^{\circ} \mathrm{C}$ (AET). The vacuum distillation was performed by stepwise lowering the vacuum from 100 , to 20 , and finally to 0.75 Torr.

Depending on the solubility behavior, the distillate fractions were further divided into three main categories: light fractions which include fractions $1-3$, obtained at atmospheric vacuum pressure, heavy fractions consisting of fractions $4-8$, extracted at low vacuum pressures, and a residual fraction consisting of 
Table 3. Results of Miscibility Studies of HTL Biocrude in SRGO in the Presence of Different Solvents and Solvent Mixtures

\begin{tabular}{|c|c|c|c|c|c|}
\hline biocrude (wt \%) & solvents & SRGO (wt \%) & biocrude miscible & immiscible residue & miscibility \\
\hline 5 & pyridine (20 wt \%) & 75 & $0.310 \mathrm{~g}$ & $0.190 \mathrm{~g}$ & $62 \%$ \\
\hline 5 & cyclohexanone (20 wt \%) & 75 & $0.325 \mathrm{~g}$ & $0.175 \mathrm{~g}$ & $65 \%$ \\
\hline 5 & pyridine-cyclohexanone (20 wt \%) & 75 & $0.360 \mathrm{~g}$ & $0.140 \mathrm{~g}$ & $72 \%$ \\
\hline 5 & pyridine-2-heptanone (20 wt \%) & 75 & $0.370 \mathrm{~g}$ & $0.130 \mathrm{~g}$ & $74 \%$ \\
\hline 10 & pyridine-cyclohexanone (20 wt \%) & 70 & $0.650 \mathrm{~g}$ & $0.350 \mathrm{~g}$ & $65 \%$ \\
\hline 10 & pyridine-2-heptanone (20 wt \%) & 70 & $0.670 \mathrm{~g}$ & $0.330 \mathrm{~g}$ & $67 \%$ \\
\hline
\end{tabular}

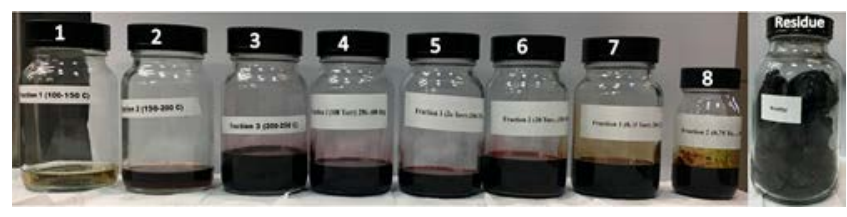

Figure 4. Picture shows the light fractions (1-3, left to right), heavy fractions (4-8, left to right), and residue (last) obtained by the fractional distillation of HTL biocrude (pinewood).

fraction 9. The yields of the individual fractional cuts and detailed summary of the fractional distillation are shown in Table S2 in the Supporting Information. The total yields of light and heavy fractions distilled during the fractional distillation of biocrude were found to be 10.43 and $22.84 \mathrm{wt}$ $\%$, respectively, while the remaining heavy distillate end of 66.14 wt $\%$ was obtained as a residue. The specific requirements to a HTL biocrude for possible coprocessing with the fossil streams depends on the coprocessing conditions and configuration of the particular refinery. The HTL biocrude requires fractional cuts having short chain aliphatics and almost no oxygen contents for the acceptable SRGO blending stock. ${ }^{34}$ Figure 5 shows the schematic illustration of the integration of HTL biocrude based on the composition into a conventional petroleum refinery for coprocessing with different fossil streams. Green lines have been used for the HTL biocrude or its components (light fractions, heavy fractions, and residue) whereas red and black lines are for the crude oil and its components. Dashed and solid green lines in Figure 5 represent the possible and actual pathways, respectively, through which HTL biocrude based on its composition and boiling ranges can be integrated into the existing refinery processes. Whereas solid red, dashed red, and dash black lines showed the existing hydrotreating processes in oil refinery for the production of different refinery streams. It was observed that the heavy fractions with low oxygenates and high aliphatic or aromatic contents resemble the SRGO structure in the conventional petroleum refinery. ${ }^{34}$ We therefore suggest that the about 22.84 wt \% of HTL biocrude (pinewood) is suitable for coprocessing with the SRGO in the petroleum refinery.

The HSPs of light, heavy, and residual fractions were also caculated according to the above-mentioned procedure with fitting values of 1.000, 0.971, and 0.934, respectively. By assigning HSPs of all samples to the Hansen double sphere approach, the predictions of their compatibilities with SRGO were made (Figure $2 \mathrm{~b}-\mathrm{d}$ ). Furthermore, RED and $R_{\mathrm{a}}$ parameters for all samples were also calculated from the solubility differences between two spheres in each case and compared to assign their relative order of miscibility. The partial overlap between the Hansen spheres of the light fraction-SRGO blend is indicative of a lower affinity of light fractions in SRGO (Figure 2c). Interestingly, the Hansen double sphere plot of the heavy fraction-SRGO blend shows the highest overlap between two spheres, which indicates the high compatibility of heavy fractions with SRGO (Figure 2b). However, the complete immiscibility of the residue in SRGO was predicted owing to the nonoverlap between their corresponding Hansen spheres (Figure 2d). To complement our predictions, RED and $R_{\mathrm{a}}$ values for the heavy fractionSRGO blend were calculated and found to be 0.359 and 4.74, respectively (Table 2 ). The significantly smaller RED and $R_{\mathrm{a}}$ values of the heavy fraction-SRGO blend suggest that the heavy fractions are highly compatible in SRGO. Interestingly, the observed distance value is in accordance with the reported compatibility limit for the center-to-center distance of blends of HTL biocrudes in refinery streams. ${ }^{28}$ However, the higher RED and $R_{\mathrm{a}}$ values of light fractions and residue to SRGO are responsible for their lower interaction potentials (Table 2). These calculations confirm the extreme compatibility of heavy fractions with SRGO as predicted from double sphere plots. The miscibility of subfractions and residue in SRGO was also checked experimentally to verify the theoretically predicted values. Different amounts of each sample were dispersed in SRGO using the vortex mixer for $15 \mathrm{~min}$ and observed after a few hours. The light fractions showed a maximum miscibility

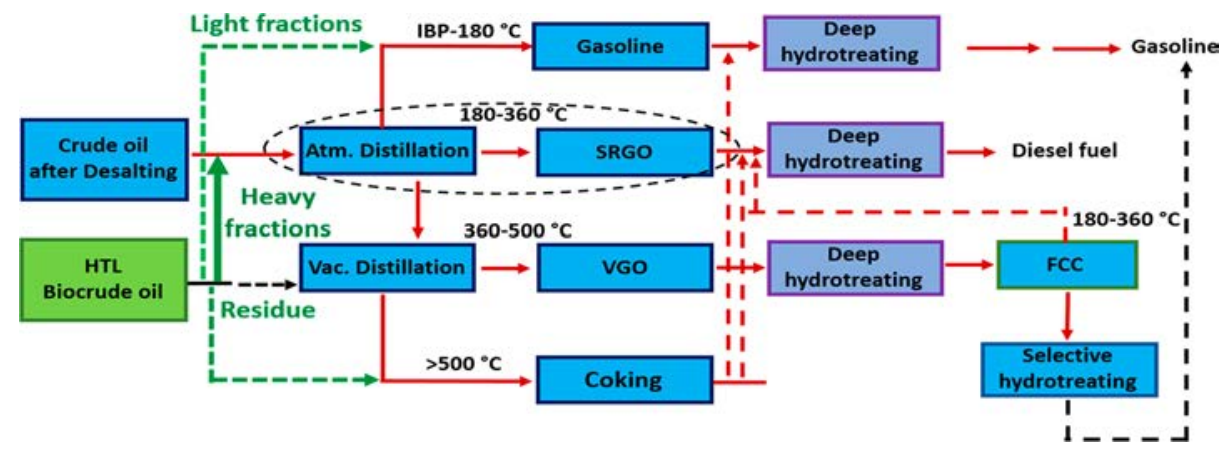

Figure 5. Schematic illustrative integration of HTL biocrude based on the boiling range of different fractional cuts into the conventional petroleum refinery for the production of drop-in biofuels. 
of 5 wt \% while the heavy fractions were completely miscible at any proportions in SRGO. As predicted from the double sphere approach and solubility parameters, the residue did not show any miscibility in SRGO. Moreover, the miscibility of upgraded bio-oil (deoxygenated) in SRGO was also checked for comparison purposes, and a complete miscibility at any proportion was noticed. These studies show that the change in polarity $\left(\delta_{\mathrm{D}}\right.$ and $\left.\delta_{\mathrm{P}}\right)$ of the components significantly affects the overlapping of two spheres and, hence, affects their mutual compatibility. The spot tests of the blends obtained during the miscibility studies were also carried out for the visual detection of precipates by casting a drop of the mixture on the filter paper. As shown in Figure 6, the biocrude-SRGO and

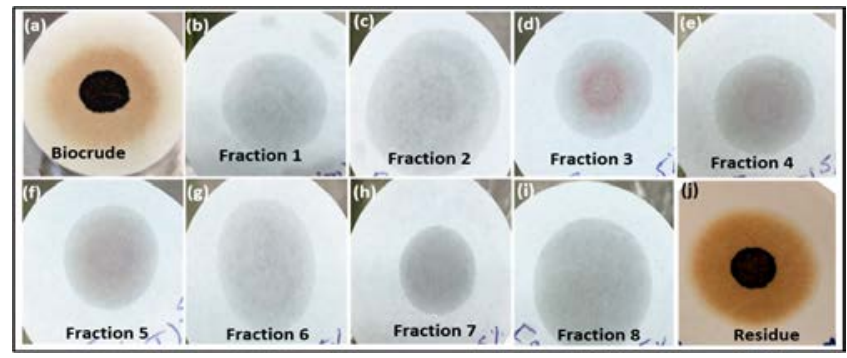

Figure 6. Spot tests for the visual detection of miscibility of $5 \mathrm{wt} \%$ (a) HTL biocrude oil, $(\mathrm{b}-\mathrm{d})$ light fractions, $(\mathrm{e}-\mathrm{i})$ heavy fractions, and $(j)$ residue in SRGO (95 wt \%).

residue-SRGO blends exhibit the presence of precipitates, whereas no such precipitates were found in the case of heavy fractions in SRGO. These studies reveal the high compatibility of heavy fractions and incompatibility of biocrude and residue in SRGO which are consistent with theoretically predicted values. Therefore, this study highlights a straightforward approach for determining the HSPs, solvent affinity, and compatibility with an acute acuracy of different substances on the basis of their solubility features.

To confirm the complete miscibility and phase separation in the blends, DSC spectra were recorded in the course of heating light, heavy, and residual fractions as well as their blends with SRGO (Figure 7). The compatibility of the blending mixtures of distillate fractions and residue with SRGO is evaluated by analyzing the vaporization temperature curves ascribed to the effect of temperature. As suggested, two broad endothermic peaks in the DSC spectra of residue-SRGO and light fraction-SRGO blending mixtures as compared to their starting precursors (e.g., the light fraction and residue) indicate two separate nonmixed phases, which confirm their immiscibility (Figure 7). Whereas, the single endothermic peak in the DSC spectrum of the heavy fraction-SRGO blend identical to pure the heavy fraction indicates a homogeneous phase, which confirms the compatibility of heavy fractions in SRGO. ${ }^{35}$

The detailed composition, properties, and distribution of oxygen contents in HTL biocrude and the light, heavy, and residual fractions were investigated using elemental analysis. For comparison, detailed specification of oxygen contents and properties of upgraded biocrude obtained by hydrotreating biocrude (pinewood) in a microbatch reactor was also analyzed. The results of the elemental analysis and properties of all the samples are shown in Table 4. The oxygen to carbon $(\mathrm{O} / \mathrm{C})$ and hydrogen to carbon $(\mathrm{H} / \mathrm{C})$ ratios indicate the variations of oxygen and aromatic or aliphatic contents present in all the samples, respectively, which may give an estimate

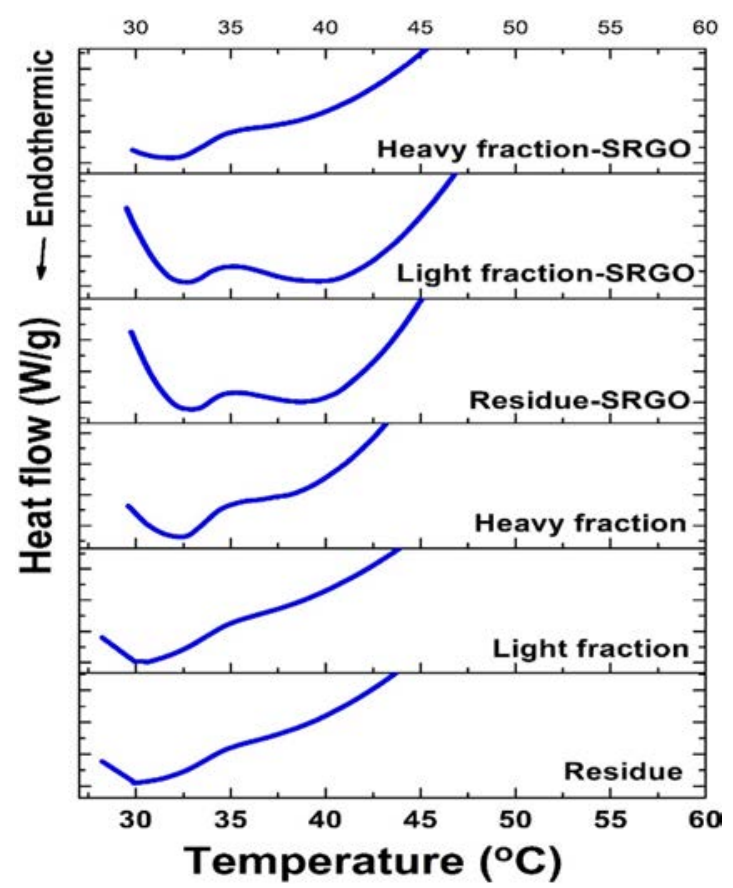

Figure 7. DSC spectra showing vaporization temperature curves of light fraction, heavy fraction, residue, light fraction-SRGO, heavy fraction-SRGO, and residue-SRGO blends.

about the chemical nature of the functional groups present in the samples. The high $\mathrm{O} / \mathrm{C}$ ratio in biocrude suggests high oxygen contents (11.5 wt \%) which are completely deoxygenated ( $0 \mathrm{wt} \%)$ during the hydrotreating experiment (Table 4, entry 2). Among distillate fractions, the decrease of both the $\mathrm{O} / \mathrm{C}$ and the $\mathrm{H} / \mathrm{C}$ ratios with increase in the boiling temperature indicates that the heavy fractions are less oxygenated but more aromatic in structure than the light fractions. These results indicate that the oxygen contents in the distillate fractions decrease with increase in AET. Similar to the heavy distillate fractions, the low $\mathrm{H} / \mathrm{C}(1.48$ wt \%) and $\mathrm{O} / \mathrm{C}$ ( 0 wt \%) ratios in the upgraded biocrude allows the extended aromaticity and lack of oxygen containing functional groups which indicate the complete expulsion of oxygen contents via hydrodeoxygenation. These studies reveal that the high compatibility of heavy fractions and upgraded biocrude in SRGO is attributed to their lower oxygen contents (low polarity) being similar to that of the SRGO structure. ${ }^{36}$ This observation correlates well with the theoretical predictions of compatibility, made from Hansen double plots. Therefore, fractional distillation plays an important role in dividing biocrude oil into different chemical groups compatible with the fossil fuels to produce drop-in biofuels.

The elemental observation was complimented by identifying the chemical functionalities along with their relative concentrations present in the biocrude and light fractions, heavy fractions, residue, and upgraded bio-oil through GC-MS analysis. GC-MS analysis of the HTL biocrude exhibited the existence of a significant amount of oxygen containing functional groups (e.g., carboxylic acids, ketones, esters, and alcohols), substituted phenolic derivatives, and a small quantity of aromatic as well as aliphatic hydrocarbons (Table S3 in the Supporting Information). The light distillate fractions contain mainly short chain carboxylic acids and cyclic ketones; however, lower concentrations of substituted aromatics, phenol 
Table 4. Elemental Composition, Properties, and Miscibility Studies of Biocrude, Upgraded Bio-oil, Light Fractions, Heavy Fractions, and Residue

\begin{tabular}{|c|c|c|c|c|c|c|c|c|c|}
\hline \multirow[b]{2}{*}{ sample } & \multirow[b]{2}{*}{ temperature $\left({ }^{\circ} \mathrm{C}\right)$} & \multirow[b]{2}{*}{ vacuum pressure } & \multirow[b]{2}{*}{$\mathrm{HHV}^{a}(\mathrm{MJ} / \mathrm{kg})$} & \multicolumn{5}{|c|}{ elemental analysis [wt \%] } & \multirow[b]{2}{*}{ miscibility in SRGO } \\
\hline & & & & $\mathrm{C}$ & $\mathrm{H}$ & $\mathrm{O}^{b}$ & $\mathrm{H} / \mathrm{C}$ & $\mathrm{O} / \mathrm{C}$ & \\
\hline biocrude & - & - & 35.9 & 80 & 8.4 & 11.5 & 1.26 & 0.11 & immiscible \\
\hline upgraded bio-oil & - & - & 45.9 & 88.8 & 11.0 & 0 & 1.48 & 0 & completely miscible \\
\hline fraction 1 & $100-150$ & atm. & 35.1 & 65.6 & 12.3 & 22.1 & 2.24 & 0.25 & $1-5 \%$ \\
\hline fraction 2 & $150-200$ & atm. & 37.9 & 78.3 & 10 & 11.7 & 1.53 & 0.11 & $1-2 \%$ \\
\hline fraction 3 & $200-250$ & atm. & 37.1 & 74.7 & 10.7 & 14.6 & 1.71 & 0.15 & $1-3 \%$ \\
\hline fraction 4 & $250-300$ & 100 Torr & 38.1 & 74.5 & 10.1 & 11.4 & 1.54 & 0.11 & completely miscible \\
\hline fraction 5 & $200-250$ & 20 Torr & 38.8 & 79.5 & 10.3 & 10.2 & 1.55 & 0.1 & completely miscible \\
\hline fraction 6 & $250-300$ & 20 Torr & 37.5 & 78.1 & 9.8 & 12.1 & 1.5 & 0.12 & completely miscible \\
\hline fraction 7 & $200-250$ & 0.75 Torr & 39.8 & 83.7 & 9.6 & 6.7 & 1.38 & 0.06 & completely miscible \\
\hline fraction 8 & $250-300$ & 0.75 Torr & 40.0 & 83. 4 & 9.1 & 7.5 & 1.31 & 0.07 & completely miscible \\
\hline residue & $>300$ & $<0.75$ Torr & 38.0 & 86.0 & 7.4 & 6.6 & 1.03 & 0.06 & immiscible \\
\hline
\end{tabular}

${ }^{a}$ Calculated by the Channiwala equation. ${ }^{b}$ Calculated by difference.

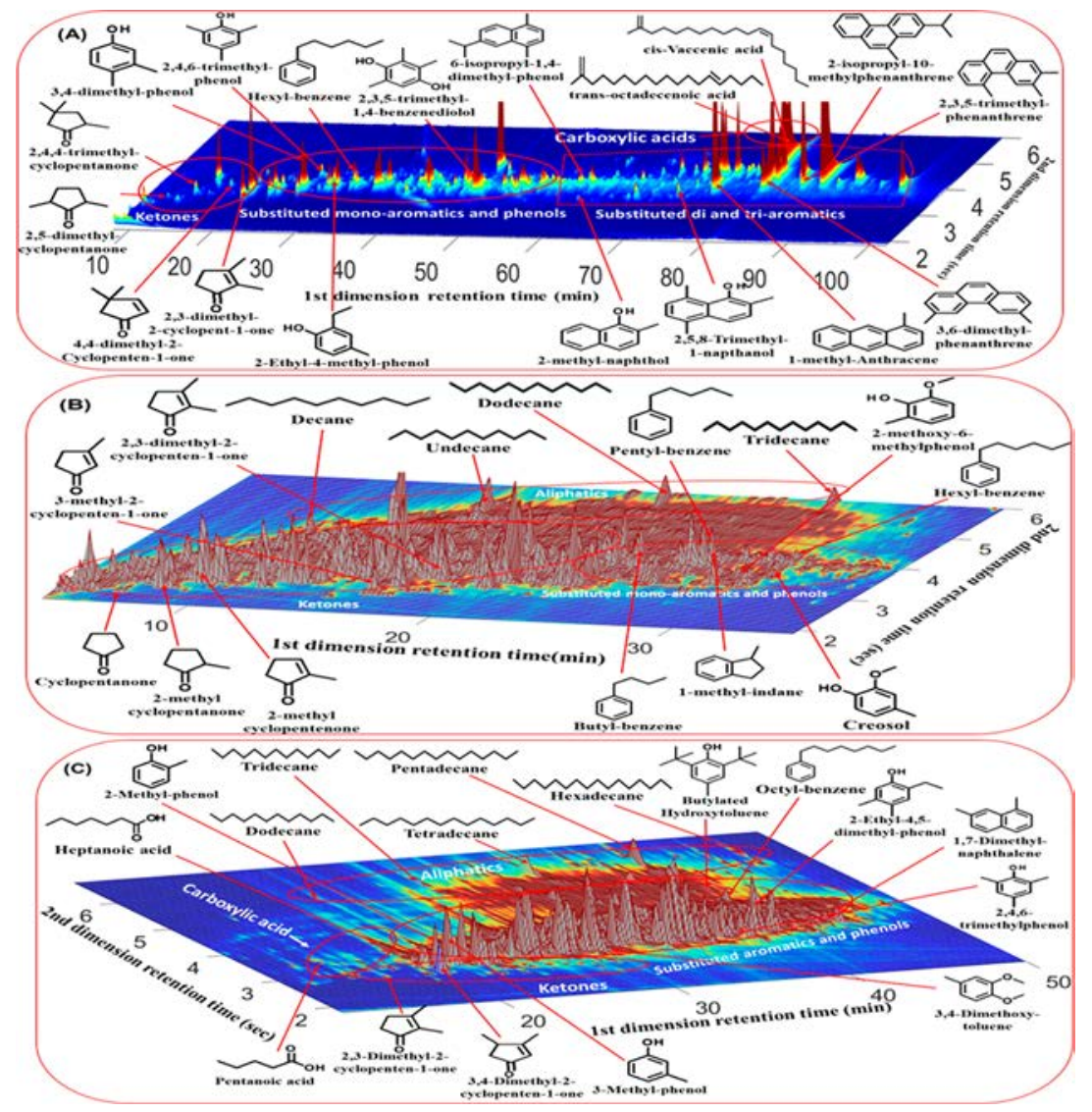

Figure 8. GC $\times$ GC-MS (3D) surface plots with group type analysis and identified major compounds in (A) HTL biocrude, (B) light fraction, and (C) heavy fraction.

derivatives, and straight chain aliphatic hydrocarbons were also observed (Table S4 in the Supporting Information). The heavy fractions are more dominated by substituted phenol and benzene derivatives, while upgraded biocrude mainly contains aliphatic (straight and branched) and substituted aromatic hydrocarbons (Tables S5 and S7 in the Supporting Information). GC-MS analysis of the residue showed only the chemical compounds below the $300{ }^{\circ} \mathrm{C}$ range. The main chemical composition of the residue includes oxygenates (e.g., carboxylic acids, ketones, aldehydes, and alcohols), nitrogenates (e.g., amides, amines, and amino acids), heterocyclic compounds (e.g., pyridine and dithianes), and substituted aromatic hydrocarbons (e.g., benzene and phenol derivatives) with a small quantity of branched aliphatic compounds (Table S6 in the Supporting Information). In contrast, the SRGO is nonpolar owing to the presence of only aliphatic and aromatic hydrocarbons as the main constituents. The presence of heteroatoms in biocrude, light fractions, and residue caused phase partitioning due to the difference in polarities between the oil and SRGO, which resulted in immiscibilities of their components. Whereas hydrodeoxygenation of HTL biocrude completely removed the heteroatoms and increased the $\mathrm{H} / \mathrm{C}$ ratio to match the polarity of SRGO and, hence, improved the compatibility. ${ }^{37}$ The GC-MS results showed that the aromatic 


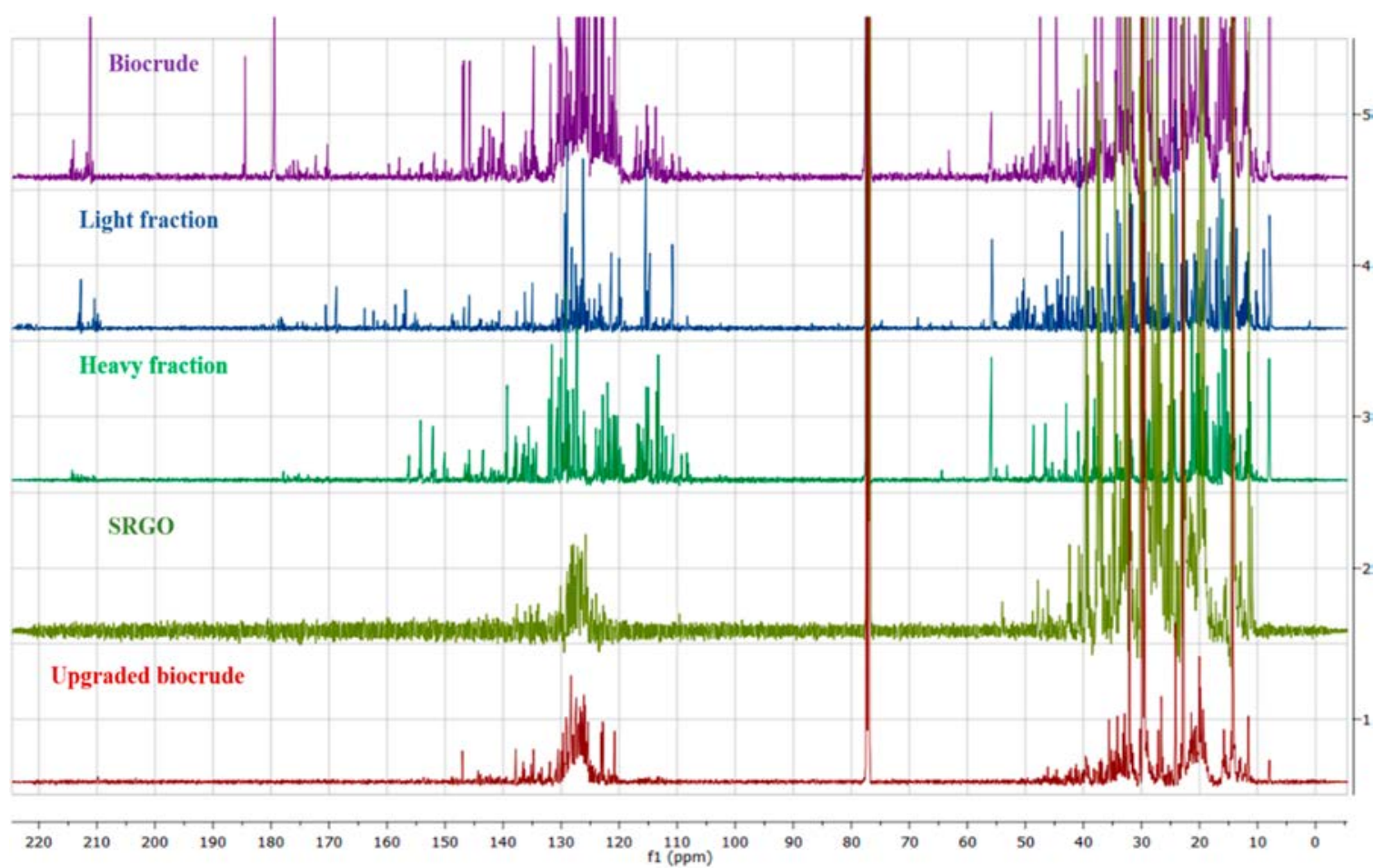

Figure 9. ${ }^{13} \mathrm{C}$ NMR spectra of biocrude, light fraction, heavy fraction, SRGO, and upgraded bio-oil.

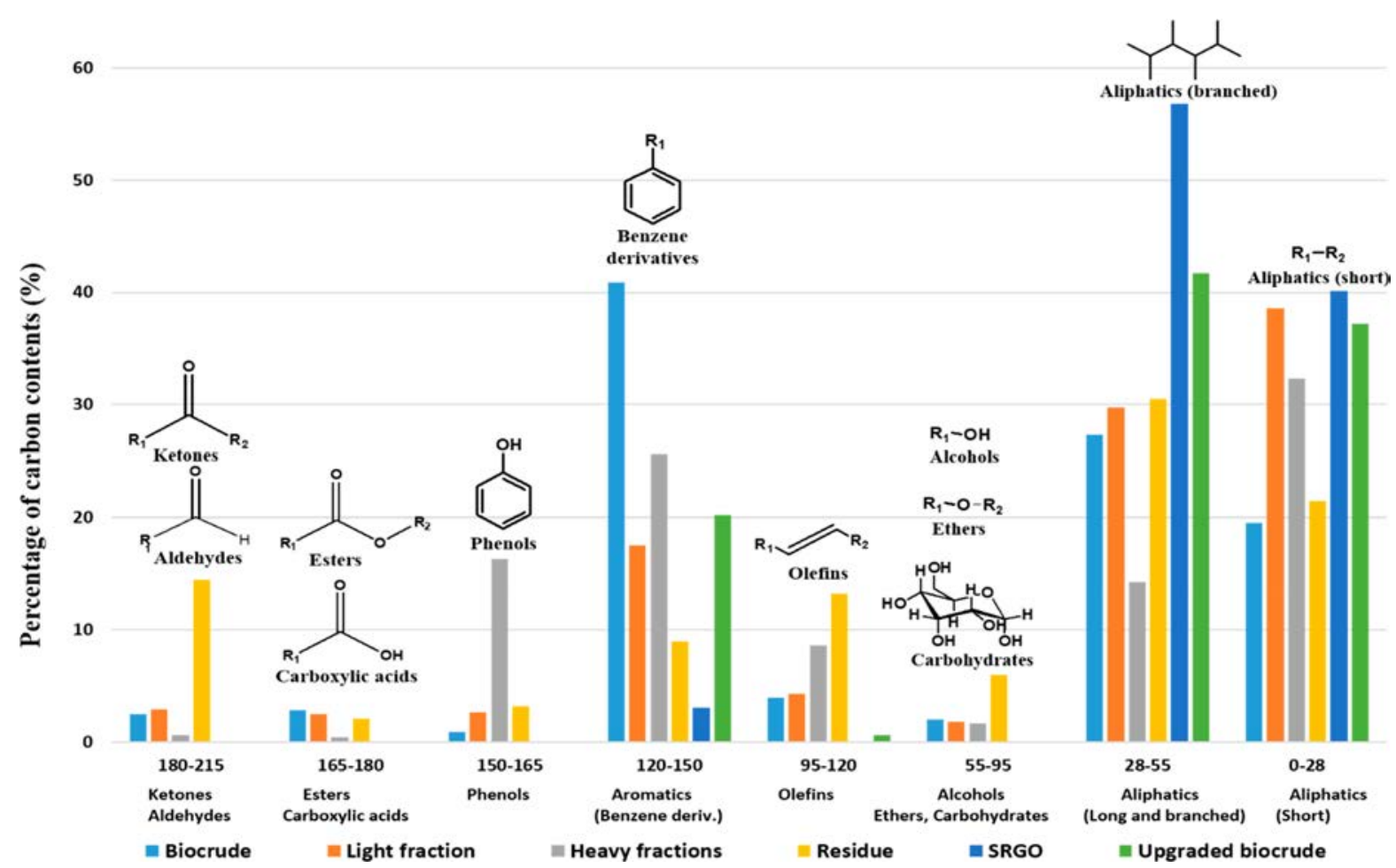

Figure 10. Quantitative analysis of ${ }^{13} \mathrm{C}$ NMR spectra of biocrude, light fraction, heavy fraction, residue, SRGO, and upgraded biocrude oil by integration of the defined chemical shift range.

and aliphatic hydrocarbon constituents present in heavy fractions significantly contribute to the compatibility with SRGO.

The GC $\times$ GC technique was also employed to gain further information about the detailed composition of molecular structures of biocrude and distillate fractions as well as to determine the tentative chemical structure of major chemical compounds. A group analysis for the different functional groups was carried out to report overall composition of biocrude and light and heavy fractions. Figure 8 shows the 3D $\mathrm{GC} \times \mathrm{GC}$ plots of the biocrude, light fractions, and heavy fractions with highlighted functional group regions with names of identified compounds. Based on the chemical functionalities, the GC $\times$ GC-MS chromatogram of biocrude is broadly 
categorized into four main groups (Figure 8A). Within the highlighted groups, four different categories of chemical compounds such as ketones (e.g., saturated and unsaturated cyclic ketones), substituted aromatic or phenolic monomers (e.g., arenes, and benzenediols), di- and triaromatics or phenolics (e.g., naphthol, anthracene, phenanthrenes, and biphenyls), and carboxylic acids were identified as the main constituents of biocrude. The presence of oxygenates such as ketones, carboxylic acids, and phenol derivatives in substantial amounts in the HTL biocrude causes a severe threat to the compatibility with SRGO. The chromatograms of light and heavy fractions were also recorded to estimate the distribution of chemical functionalities. The highlighted chemical functionality regions in the chromatogram of light fractions showed three main classes of chemical compounds including ketones (e.g., cyclic ketones), substituted aromatics or phenolics (e.g., arenes, methyl or methoxyphenols, methoxytoluene, naphthalene, and benzenediols), and aliphatics (e.g., n-alkanes) (Figure 8B).

As shown in Figure 8C, the chromatogram of heavy fractions was divided into four different regions with carboxylic acids, ketones, substituted aromatics, or phenolics and aliphatics as the main chemical compounds. The group analysis shows that the areas under the aromatic and aliphatic regions in the chromatogram of heavy fractions are higher than that of light fractions, which indicate the higher aromatic and aliphatic contents in the heavy fractions, whereas the area under oxygen containing functional groups is higher in light fractions. The heavy fractions with higher aromatic and aliphatic contents can be expected to show high compatibility in SRGO. For comparison, the GC $\times \mathrm{GC}$ color plots of all the distillate fractions $(1-8)$ are also provided in Figures $\mathrm{S} 1-\mathrm{S} 8$ in the Supporting Information. Unfortunately, the GC $\times$ GC chromatogram of the residue could not be recorded due to the presence of high boiling complex residual fractions. ${ }^{38}$ The general trend observed on the distribution of functional groups based on identified chemical compounds complies with the results of elemental and GC-MS analysis. These results confirm that the utilization of the GC $\times$ GC-MS technique for the estimation of molecular structure plays a crucial role in the determination of the compatibility of biocrude.

To correlate the interactions within the blend components with the compatibility of biocrude, subfractions, and residue, ${ }^{13} \mathrm{C}$ NMR spectra of all the samples were recorded. Figure 9 shows the overlay ${ }^{13} \mathrm{C}$ NMR spectra of all derivatives. ${ }^{13} \mathrm{C}$ NMR analyses provide useful information on the type and relative percentage of chemical functionalities present in biooils. A quantitative evaluation of the chemical functional groups present in all the samples was also determined by integrating the specific regions of the ${ }^{13} \mathrm{C}$ NMR spectra according to different chemical shift values. A summary of the percentage of total carbon contents within a particular chemical shift range is discussed in Figure 10 and Table S7 in the Supporting Information. The observed chemical compositions of all the samples from the ${ }^{13} \mathrm{C}$ NMR analysis were found to be consistent with the elemental compositions calculated by $\mathrm{CHN} / \mathrm{O}$ analysis. The whole chemical shift range in each spectrum is distributed into eight regions excluding the $\mathrm{CDCl}_{3}$ solvent peak $(77.2 \mathrm{ppm})$. These regions are $0-28,28-$ $55,55-95,95-120,120-150,150-165,165-180$, and 180$215 \mathrm{ppm}$ which correspond to short aliphatics, branched aliphatics, alcohols, olefins, aromatics, phenols, carboxylic acids, ketones, or aldehydes, respectively. The chemical shift region $0-55 \mathrm{ppm}$ covers all kinds of saturated hydrocarbons including short (0-28 ppm), long, and branched chain aliphatics $(28-55 \mathrm{ppm})$. The region $55-95 \mathrm{ppm}$ in ${ }^{13} \mathrm{C}$ NMR spectra provides useful information about the oxygen containing functional groups present in all the samples. Particularly, this region corresponds to the carbon adjacent to oxygen, e.g., alcohols, ethers, carbohydrates, and hydroxyl groups from lignin and methoxy-benzenes. The integrated region 95-120 ppm represents the two main categories including acyclic or cyclic olefins and mono- or diolefins. The next chemical shift region is $120-150 \mathrm{ppm}$ which corresponds to aromatic hydrocarbons, including substituted benzene derivatives (e.g., alkyl or aryl benzenes) and heteroaromatics (e.g., pyridine). The chemical functionalities with aromatic contents are important due to their stronger $\pi$ electron interactions (e.g., $\pi-\pi$ stacking interactions) that play an important role in the determination of blend properties. ${ }^{39}$ The next downfield part of the ${ }^{13} \mathrm{C}$ NMR spectra lies between 150 and $165 \mathrm{ppm}$, which accounts for the substituted phenol derivatives. The final integrated region of the spectra is the lowest downfield end that lies between 165 and $215 \mathrm{ppm}$, which represents the carbonyl group. This region is further subdivided into 165-180 ppm (esters and carboxylic acids) and 180-215 ppm (ketones and aldehydes). Among the above-mentioned regions, the chemical shift regions corresponding to the alkyl hydrocarbons are of main interest due to the significant contribution of aliphatic groups to the energy content of biofuels. ${ }^{40}{ }^{13} \mathrm{C}$ NMR results revealed the presence of branched chain aliphatics (27.23 wt \%), short chain aliphatics (19.50 wt \%), aromatic contents (41.73 wt \%), and total oxygenates adjacent to carbon atoms $(7.60 \mathrm{wt} \%)$ in HTL biocrude (Table S8 in the Supporting Information). Oxygenates in raw biocrude indicate the presence of components with oxygenated polar compounds having moderate-to-high acidity. ${ }^{41}$ The carbon contents corresponding to the oxygen containing functional groups are present in higher concentration in the residue (22.57 wt \%) than in light fractions (7.48 wt \%) and heavy fractions (2.72 wt \%). The total aromatic carbon contents including phenols of heavy, light, and residual fractions were found to be 42.77, 21.35, and $12.19 \mathrm{wt} \%$, respectively. These results indicate that the oxygen containing groups such as ketones, aldehydes, carboxylic acids, esters, and alcohols are present in substantial amounts in the HTL biocrude, light fractions, and residue, which affect their stability and compatibility. ${ }^{37}$ Based on the NMR results the correlations of the carbon contents of the oxygen containing functional groups vs total carbon in aromatics for the increment in miscibility of light, heavy, and residual fractions in SRGO were also demonstrated (Figure S9 in the Supporting Information). It was observed that the molecular structure of the biocrude and its components plays a crucial role in determining their compatibility in the SRGO. The basic differences between the physicochemical properties of these derivatives are attributed to the different functional groups within their molecular structure.

Generally, the compatibility of two mixtures depends on the similarity of their compound structure such as mixtures with only alkanes or only aromatics, which exhibit extreme compatibility. ${ }^{42}$ The NMR analysis showed that SRGO is nonpolar owing to the absence of any oxygen containing carbon atom and phenolic derivatives (Figure 10 and Table S7 in the Supporting Information). Furthermore, the aliphatic and aromatic carbon contents in SRGO were found to be 96.94 
and 3.05 wt \%, respectively. Therefore, one needs structurally similar compounds to be compatible with SRGO. According to the correlation between carbon containing oxygen atoms and aromatic carbons (Figure S9 in the Supporting Information), the miscibility of distillate fractions of HTL biocrude and its components in SRGO exhibits the following order: residue < light fractions < heavy fractions. The above order of the miscibility is found to be consistent with the theoretically predicted values from the Hansen solubility approach and the experimental data of miscibility studies. The high miscibility of heavy fractions in SRGO is attributed to the presence of aromatic contents, as well as low oxygen contents, which reduce their polar characteristics being similar to the SRGO structure. Aromatic rings present in heavy fractions may interact strongly with the $\pi$ electron cloud of SRGO through $\pi-\pi$ stacking interactions which results in reasonable compatibility. ${ }^{43}$ Apart from the $\pi-\pi$ stacking interactions, the carbonyl groups in heavy fractions can also interact with the aromatic rings of SRGO through noncovalent interactions. ${ }^{44}$ The competitive interactions between the lone pair of electrons on the carbonyl groups of heavy fractions and the face of the $\pi$ system of aromatic units of SRGO were confirmed by ${ }^{13} \mathrm{C}$ NMR spectroscopy. These interactions induced structural changes, as evidenced from the diminishing of carbonyl signals in the ${ }^{13} \mathrm{C}$ NMR spectrum of the heavy fraction-SRGO blend (Figure $\mathrm{S} 10$ in the Supporting Information). These structural changes in the heavy fraction-SRGO blend again confirm the complete miscibility of their corresponding components. ${ }^{15}$ These results showed that the combined effect of $\pi-\pi$ and lone pair $-\pi$ interactions between the functional groups lead to changing structure and properties of the blends. On the other hand, for more oxygen content present in biocrude, light fractions and residue do not match with the SRGO structure, and this mismatch caused their incompatibility. To support our hypothesis, the ${ }^{13} \mathrm{C}$ NMR spectrum of upgraded biocrude was also recorded. The ${ }^{13} \mathrm{C}$ NMR spectrum of upgraded biocrude revealed that the hydrodeoxygenation of HTL biocrude not only removed the oxygen contents but also reduced the aromatic contents (Figure 9). Specifically, a single-step hydrotreating of HTL biocrude at a $350{ }^{\circ} \mathrm{C}$ temperature and $6 \mathrm{MPa}$ pressure caused a reduction of aromatic carbon from $40.79 \%$ to $20.21 \%$ ( $50 \mathrm{wt}$ $\%)$ aromatic carbons. The decrease of the aromatic carbon contents and the increase of the aliphatic carbon contents indicate that the provided hydrotreating conditions resulted in a high degree of saturation and dearomatization of biocrude, leading to a more aliphatic nature of bio-oil compatible with SRGO (Figure 10). Consequently, the ${ }^{13} \mathrm{C}$ NMR spectrum of upgraded biocrude exhibited high aliphatic (78.94 wt \%) and low aromatic contents $(20.26 \mathrm{wt} \%)$ with almost no oxygenates (0.14 wt \%). These results comply well with the experimental miscibility results of upgraded bio-oil. These results confirmed that the difference in properties and incompatibility of HTL biocrude with those of SRGO is primarily due to the high oxygen contents that should be removed in order to blend appreciable volumes in conventional diesel and gasoline fuels. The present study proved that the fractional distillation is an efficient concept for the separation of oxygen rich light fractions from raw biocrude to improve its compatibility with SRGO. The very low polarity changes by decreasing oxygen contents suggest that these biocrudes would be expected to be highly compatible with the SRGO. It is envisioned that the HTL biocrudes with low oxygen contents (polarity) can be expected to show high compatibility with the fossil fuels compared to SRGO for cost-effective corefining processes.

\section{EXPERIMENTAL SECTION}

Materials. Biocrude for the present study was produced from pinewood with supercritical water via HTL at the continuous Bench Scale 1 (CBS1) facility with $1 / 3$ barrel/day capacity at Aalborg University, Denmark. ${ }^{45}$ The SRGO used in the miscibility studies was provided by MOL refinery, Hungry. All 38 solvents (Table S1 in the Supporting Information) used for the miscibility studies were purchased from Sigma-Aldrich Co. Ltd.

Characterization Techniques. Proton decoupled ${ }^{13} \mathrm{C}$ NMR spectra of biocrude, subfractions, residue, and upgraded biocrude were recorded in $\mathrm{CDCl}_{3}$ solvent at $150.9 \mathrm{MHz}$ on a Bruker Avance III 600 spectrometer. Typically, $20-30 \mathrm{mg}$ of each oil sample was completely dissolved in $600 \mu \mathrm{L}$ of $\mathrm{CDCl}_{3}$ (chloroform- $\left.d_{1}\right)$. However, the same amount of residue was maximally dissolved in $1 \mathrm{~mL}$ of $\mathrm{CDCl}_{3}$, and the resulting solution was filtered to remove the insoluble portion. ${ }^{13} \mathrm{C}$ NMR spectra of subfractions and upgraded biocrude were acquired at 1024 scans, while 4096 scans were given to record the NMR spectra of biocrude and residue. The baseline corrections, peak integrations, and quantitative analysis of each spectrum were done using the MestReNova software. Elemental analysis of each sample was performed on the elemental analyzer (PerkinElmer, 2400 Series II CHNS/O) using acetanilide as a standard material for the calibration. The analysis was performed in $\mathrm{CHN}$ mode, and oxygen contents were calculated by the difference. The moisture contents of the HTL biocrude was measured on a moisture analyzer (Kern, MLS). Qualitative analysis of the biocrude, subfractions, and upgraded biocrude samples was performed by using a GC-MS instrument equipped with a gas chromatograph (Thermo Scientific, Trace 1300) and a mass spectrometer (ISQ QD). For the further identification of chemical compounds, all the samples in the liquid state were also analyzed by a GC $\times$ GC spectrometer. The whole setup consists of a $6890 \mathrm{~N}$ gas chromatograph (Agilent) equipped with a low temperature valve $\left(-100{ }^{\circ} \mathrm{C}<T<-120^{\circ} \mathrm{C}\right)$ for the narrow pulses, a two stage thermal modulator (Zoex Corporation), and a mass selective detector 5975B (Agilent) for the analysis of column effluents. A thermal desorption of samples occurs at a $280{ }^{\circ} \mathrm{C}$ temperature in the first column which injects the trapped solutes into the second column. The raw GC $\times$ GC data (cdf files) were processed for $2 \mathrm{D}$ and $3 \mathrm{D}$ plots using MATLAB software. Component interactions and miscibility of blending mixtures of light fraction, heavy fraction, and residue with SRGO were determined by analyzing the vaporization temperature curves using a DSC instrument (TA Instruments Q2000, Netzsch STA 409 PC, Netzsch STA 409 PC). Fractional distillation of the HTL biocrude was carried out according to ASTM standard D2892 on a lab scale big sized distillation setup containing a 15 theoretical plate column with an internal diameter of $25 \mathrm{~mm}$, surrounded by a heating jacket. The distillation setup consists of a RBF (round-bottom flask) of $2 \mathrm{~L}$ at the bottom of the column and 8 fractionation receivers with a capacity of $250 \mathrm{~mL}$ each. The HSPiP software package (ver. 5.0.13) (6) $^{46}$ was used to access the HSP database of solvents and to construct the Hansen solubility sphere with a fitting algorithm, using solubility test scores of 0 or 1 . The Hansen double sphere feature is installed in genetic algorithm mode in HSPiP software for the best-fit results within smallest radius. HSPs for a wide range of solvents and polymers tabulated in the HSPs library can be found in the HSPiP software.

Methods. HSPs and the Hansen Double Sphere Method. According to the Hansen solubility approach, total cohesive energy is decomposed into three main terms of dispersive $\left(\delta_{\mathrm{D}}\right)$, polar $\left(\delta_{\mathrm{P}}\right)$, and hydrogen bonding $\left(\delta_{\mathrm{H}}\right)$ interactions (eq 1$)$.

$$
\delta_{T}^{2}=\delta_{D}^{2}+\delta_{P}^{2}+\delta_{H}^{2}
$$

The extent of affinity of two materials depends on the difference between their HSPs which is evaluated by the relative energy difference (RED) values (eq 2). ${ }^{25}$ 


$$
\begin{aligned}
& \mathrm{RED}=R_{\mathrm{a}} / R_{\mathrm{o}} \\
& R_{\mathrm{a}}=\sqrt{4\left|\delta_{\mathrm{D}, 1}-\delta_{\mathrm{D}, 2}\right|^{2}+\left|\delta_{\mathrm{P}, 1}-\delta_{\mathrm{P}, 2}\right|^{2}+\left|\delta_{\mathrm{H}, 1}-\delta_{\mathrm{H}, 2}\right|^{2}}
\end{aligned}
$$

where $R_{\mathrm{a}}$ and $R_{\mathrm{o}}$ are the modified difference between the HSPs of two substances and the radius of the Hansen sphere, respectively. If RED $<1$, the two solvents are mutually soluble, if RED $=1$ they are partially soluble, and if RED > 1 they are insoluble. In simple terms, if the distance $\left(R_{\mathrm{a}}\right)$ between two substances is small then, they have a high tendency of being miscible (eq 3 ).

In the Hansen single sphere plot, the HSPs of different solvents and a substance are plotted in a three-dimensional space in which good solvents for the substance exist inside the sphere while the poor solvents are placed outside the sphere. The HSPs of the final substance are represented by the center of the three-dimensional sphere with the radius of the sphere considered as the radius of interaction. In comparison to the single sphere plot, the double sphere plot is extremely explicit in determining the volume of area overlap between the two spheres which provides actual information on the extent of compatibility of two substances. ${ }^{32}$ Furthermore, the difference in HSPs (RED) and solubility distance $\left(R_{\mathrm{a}}\right)$ between two substances can be easily determined from the center of each sphere. ${ }^{26}$ Additionally, the affinity of different solvents for the immiscible substances can be easily determined from their distance from the junction between the two spheres. HSPs can help to determine and improve the compatibility of biocrudes, heavy fractions, bitumens, asphaltenes, and residues with existing petroleum crudes to achieve a drop-in biofuel for processing in conventional refineries. In the present work, we used the Hansen double sphere method to determine the compatibility of HTL biocrude, light fraction, heavy fraction, and residue with SRGO, which were found to be consistent with the experimental miscibility results. Furthermore, the affinity of different solvents for the biocrude-SRGO mixture was also studied from their distance $\left(R_{\mathrm{a}}\right)$ from the junction of the blending mixture, and a close relationship with experimental data on miscibility was verified.

Determination of HSPs. The solubility of each of the samples was measured experimentally in 38 different solvents using the standard procedure $^{31}$ (Table S1 in the Supporting Information), and corresponding HSPs (Table 1) were calculated by plotting a threedimensional Hansen solubility plot. Typically, approximately $0.5 \mathrm{~g}$ of each sample is blended in $5 \mathrm{~mL}$ of different solvents using a vortex shaker for 10-15 min. Then, the blends are left undisturbed for $48 \mathrm{~h}$ to allow for complete dissolution or settlement. Hereafter, each of the test solvents is evaluated as good and bad on a binary scale; 1 means completely soluble and hence a "good" solvent and 0 for insoluble and hence a "bad" solvent for that particular sample. Due to the dark black color of the solutions (except for SRGO), visual inspection of the obtained solutions was done by the spot test on a filter paper. If a black ring structure was found on the filter paper, the test solvent was assigned to be a bad solvent (score 0 ), while the completely soluble solutions were contemplated to designate a good solvent (score 1). HSPiP software (Ver. 5.0.13) was employed to plot Hansen solubility spheres for each sample, and HSP values were calculated from the center coordinates of the resulting solubility sphere.

Fractional Distillation of Biocrude. Prior to fractional distillation, approximately $1.2 \mathrm{~L}$ of HTL biocrude was dehydrated at a vacuum pressure of 100 bar and vapor temperature of $130^{\circ} \mathrm{C}$ through vacuum distillation in a stand-alone setup. To ensure the bubbling, $15 \mathrm{~g}$ of boiling stones have been added into the flask. To ensure the adiabatic conditions, the jacket temperature was kept at $0-5{ }^{\circ} \mathrm{C}$ lower than the $\mathrm{AET}$ vapor temperature during the distillation and a total reflux for around 15 min was carried out. The fractional distillation of biocrude was performed at different conditions ranging from atmospheric pressure to 0.75 Torr vacuum pressures and 75 to approximately 370 ${ }^{\circ} \mathrm{C}$ AET temperature. A column to fraction collector reflux ratio of 5:1 was maintained during the distillation for vacuum pressure $>10$ Torr and a reflux ratio of 2:1 for $<10$ Torr. The fractions were collected at different vacuum pressures from atmospheric to 0.75 Torr with a temperature interval of $25^{\circ} \mathrm{C}$. To avoid the thermal cracking, the RBF temperature and the vapor temperature were maintained below 310 and $210{ }^{\circ} \mathrm{C}$, respectively. ${ }^{47}$ Vapor temperature, vacuum pressure, RBF temperature, RBF skin temperature, and volume of fractions are recorded about every $2 \mathrm{~min}$. The vapor temperature recorded during the collection of the different fractional cuts was converted to AET by using the ASTM standard D5236. ${ }^{48}$

Miscibility Studies. HTL biocrudes obtained from pinewood (1-5 wt \%) and SRGO (95-99 wt \%) were blended in a dry plastic vial using the vortex mixer for $15 \mathrm{~min}$. To improve the miscibility of the blending mixture, pyridine, cyclohexanone, and their respective $(1: 1)$ mixtures (20 wt \%) were mixed to blend with biocrude (5-10 wt \%) and SRGO (70-75 wt \%) under continuous stirring at ambient conditions. The resulting mixture was heated at $60{ }^{\circ} \mathrm{C}$ on a stirrer for $1 \mathrm{~h}$, and nonionic surfactants (span 80 and Tween 80 ) were also employed to facilitate the miscibility of biocrude in SRGO. Furthermore, the miscibility of different proportions of residue and light and heavy fractions obtained from fractional distillation of biocrude were also checked in SRGO under similar conditions to evaluate the effect of molecular structure on the compatibility of HTL biocrude. Additionally, the spot tests were also performed by spreading a drop of blends of subfractions, biocrude, and residues in SRGO on the filter paper for the visual evaluation of the compatibility of the blending mixtures.

\section{CONCLUSION}

For the first time, the Hansen double sphere approach has been successfully applied to predict the compatibility of the HTL biocrude and subfractions with SRGO. Furthermore, this approach also described the affinities of different solvents and solvent mixtures in term of their polarities to enhance the compatibility of a material blend. The correlation between the compatibility and the molecular structure of the HTL biocrude was established by investigating the compatibility of light fractions, heavy fractions, and residue obtained by the fractional distillation of HTL biocrude. The compatibility of blends was verified from the $R_{\mathrm{a}}$ and RED values as well as experimental miscibility studies. The DSC thermograms and spot tests showed complete miscibility of heavy fractions in SRGO. The qualitative techniques like elemental analysis $(\mathrm{CHN} / \mathrm{O}), \mathrm{GC}-\mathrm{MS}$, and GC $\times$ GC spectroscopies showed the presence of high aromatic and oxygen contents in HTL biocrude. Quantitative ${ }^{13} \mathrm{C}$ NMR analysis of all the samples revealed that the nonaromatic oxygenates present in HTL biocrude, light fractions, and residue pose a severe threat to the compatibility, while the heavy distillate ends and upgraded biocrude oil with low oxygenates improve the compatibility. Both theoretical predictions and experimental investigation showed that a change in the polarity of the components affects their physicochemical properties and, hence, alters their compatibility. The present study proved that fractional distillation is an efficient concept for the separation of biocrude into the chemical groups of different polarities, having high compatibility and affinity for the fossil fuels. Furthermore, we believe that the use of the Hansen double sphere approach will be advantageous toward developing a mixing strategy to assess the compatibility of biocrude oils, heavy distillate fractions, asphaltenes, residues, and polymers with existing petroleum infrastructure for the cost-effective and sustainable biorefinery processes.

\section{ASSOCIATED CONTENT}

\section{Supporting Information}

The Supporting Information is available free of charge at https://pubs.acs.org/doi/10.1021/acssuschemeng.9b06253. 
Detailed illustration of solubility scores, biocrude distillation, GC-MS, GC $\times$ GC, and ${ }^{13} \mathrm{C}$ NMR spectra of distillation products as well as correlation between carbon containing oxygen atoms and aromatic carbons (PDF)

\section{AUTHOR INFORMATION \\ Corresponding Author}

Lasse Aistrup Rosendahl - Department of Energy Technology, Aalborg University, 9220 Aalborg Øst, Denmark; 이이. orcid.org/ 0000-0002-5973-8136; Email: lar@et.aau.dk

\section{Authors}

Kamaldeep Sharma - Department of Energy Technology, Aalborg University, 9220 Aalborg Øst, Denmark; ๑ orcid.org/ 0000-0002-1471-9097

Thomas Helmer Pedersen - Department of Energy Technology, Aalborg University, 9220 Aalborg Øst, Denmark

Saqib Sohail Toor - Department of Energy Technology, Aalborg University, 9220 Aalborg Øst, Denmark

Yves Schuurman - Institut de recherches sur la catalyse et l'environnement de Lyon (IRCELYON), UMR5256, CNRS Universite Claude Bernard Lyon 1, 69626 Cedex Villeurbanne, France; $\odot$ orcid.org/0000-0002-2936-0910

Complete contact information is available at: https://pubs.acs.org/10.1021/acssuschemeng.9b06253

\section{Notes}

The authors declare no competing financial interest.

\section{ACKNOWLEDGMENTS}

This research acknowledges support from "4REFINERY" (Grant Agreement No. 727531) project, funded by the European Union's Horizon 2020 research and innovation programs.

\section{REFERENCES}

(1) Marsh, G. Biofuels: aviation alternative? Renewable Energy Focus 2008, 9, 48-51.

(2) Gollakota, A. R. K.; Kishore, N.; Gu, S. A review on hydrothermal liquefaction of biomass. Renewable Sustainable Energy Rev. 2018, 81, 1378-1392.

(3) Olcay, H.; Malina, R.; Upadhye, A. A.; Hileman, J. I.; Huber, G. W.; Barrett, S. R. H. Techno-economic and environmental evaluation of producing chemicals and drop-in aviation biofuels via aqueous phase processing. Energy Environ. Sci. 2018, 11, 2085-2101.

(4) Dimitriadis, A.; Bezergianni, S. Hydrothermal liquefaction of various biomass and waste feedstocks for biocrude production: A state of the art review. Renewable Sustainable Energy Rev. 2017, 68, 113125.

(5) Castello, D.; Pedersen, T. H.; Rosendahl, L. A. Continuous Hydrothermal Liquefaction of Biomass: A Critical Review. Energies 2018, 11, 3165.

(6) Baloch, H. A.; Nizamuddin, S.; Siddiqui, M. T. H.; Riaz, S.; Jatoi, A. S.; Dumbre, D. K.; Mubarak, N. M.; Srinivasan, M. P.; Griffin, G. J. Recent advances in production and upgrading of bio-oil from biomass: A critical overview. J. Environ. Chem. Eng. 2018, 6, 51015118.

(7) Chen, W.-T.; Zhang, Y.; Lee, T. H.; Wu, Z.; Si, B.; Lee, C.-F. F.; Lin, A.; Sharma, B. K. Renewable diesel blendstocks produced by hydrothermal liquefaction of wet biowaste. Nature Sustainability 2018, $1,702-710$.

(8) Bjelić, S.; Yu, J.; Iversen, B. B.; Glasius, M.; Biller, P. Detailed Investigation into the Asphaltene Fraction of Hydrothermal
Liquefaction Derived Bio-Crude and Hydrotreated Bio-Crudes. Energy Fuels 2018, 32, 3579-3587.

(9) Cole, A.; Dinburg, Y.; Haynes, B. S.; He, Y.; Herskowitz, M.; Jazrawi, C.; Landau, M.; Liang, X.; Magnusson, M.; Maschmeyer, T.; Masters, A. F.; Meiri, N.; Neveux, N.; de Nys, R.; Paul, N.; Rabaev, M.; Vidruk-Nehemya, R.; Yuen, A. K. L. From macroalgae to liquid fuel via waste-water remediation, hydrothermal upgrading, carbon dioxide hydrogenation and hydrotreating. Energy Environ. Sci. 2016, 9, $1828-1840$.

(10) Haghighat, P.; Montanez, A.; Aguilera, G. R.; Rodriguez Guerrero, J. K.; Karatzos, S.; Clarke, M. A.; McCaffrey, W. Hydrotreating of Hydrofaction biocrude in the presence of presulfided commercial catalysts. Sustainable Energy Fuels 2019, 3, 744-759.

(11) Castello, D.; Haider, M. S.; Rosendahl, L. A. Catalytic upgrading of hydrothermal liquefaction biocrudes: Different challenges for different feedstocks. Renewable Energy 2019, 141, 420-430.

(12) Palardy, O.; Behnke, C.; Laurens, L. M. L. Fatty Amide Determination in Neutral Molecular Fractions of Green Crude Hydrothermal Liquefaction Oils From Algal Biomass. Energy Fuels 2017, 31, 8275-8282.

(13) Nabi, M. N.; Rahman, M. M.; Islam, M. A.; Hossain, F. M.; Brooks, P.; Rowlands, W. N.; Tulloch, J.; Ristovski, Z. D.; Brown, R. J. Fuel characterisation, engine performance, combustion and exhaust emissions with a new renewable Licella biofuel. Energy Convers. Manage. 2015, 96, 588-598.

(14) Howell, J.; Roesing, M.; Boucher, D. A Functional Approach to Solubility Parameter Computations. J. Phys. Chem. B 2017, 121, 4191-4201.

(15) Romhányi, V.; Kun, D.; Pukanszky, B. Correlations among Miscibility, Structure and Properties in Thermoplastic Polymer/ Lignin Blends. ACS Sustainable Chem. Eng. 2018, 6, 14323-14331.

(16) Barton, A. F. M. Solubility Parameters. Chem. Rev. 1975, 75, 731-753.

(17) Redelius, P. G. Solubility parameters and bitumen. Fuel 2000, 79, 27-35.

(18) Wang, X.; Xu, Z.; Zhao, S.; Xu, C.; Chung, K. H. Solubility Parameters of Bitumen-Derived Narrow Vacuum Resid Fractions. Energy Fuels 2009, 23, 386-391.

(19) Milliman, H. W.; Boris, D.; Schiraldi, D. A. Experimental Determination of Hansen Solubility Parameters for Select POSS and Polymer Compounds as a Guide to POSS-Polymer Interaction Potentials. Macromolecules 2012, 45, 1931-1936.

(20) Barry, C. P.; Morose, G. J.; Begin, K.; Atwater, M.; Hansen, C. $\mathrm{J}$. The identification and screening of lower toxicity solvents for contact adhesives. Int. J. Adhes. Adhes. 2017, 78, 174-181.

(21) Guenthner, A. J.; Lamison, K. R.; Lubin, L. M.; Haddad, T. S.; Mabry, J. M. Hansen Solubility Parameters for Octahedral Oligomeric Silsesquioxanes. Ind. Eng. Chem. Res. 2012, 51, 12282-12293.

(22) Salavagione, H. J.; Sherwood, J.; De Bruyn, M.; Budarin, V. L.; Ellis, G. J.; Clark, J. H.; Shuttleworth, P. S. Identification of high performance solvents for the sustainable processing of graphene. Green Chem. 2017, 19, 2550-2560.

(23) Bergin, S. D.; Sun, Z.; Rickard, D.; Streich, P. V.; Hamilton, J. P.; Coleman, J. N. Multicomponent Solubility Parameters for SingleWalled Carbon Nanotube-Solvent Mixtures. ACS Nano 2009, 3, 2340-2350.

(24) Turpin, E. R.; Taresco, V.; Al-Hachami, W. A.; Booth, J.; Treacher, K.; Tomasi, S.; Alexander, C.; Burley, J.; Laughton, C. A.; Garnett, M. C. In Silico Screening for Solid Dispersions: The Trouble with Solubility Parameters and $\chi \mathrm{FH}$. Mol. Pharmaceutics 2018, 15, 4654-4667.

(25) Morimoto, M.; Fukatsu, N.; Tanaka, R.; Takanohashi, T.; Kumagai, H.; Morita, T.; Tykwinski, R. R.; Scott, D. E.; Stryker, J. M.; Gray, M. R.; Sato, T.; Yamamoto, H. Determination of Hansen Solubility Parameters of Asphaltene Model Compounds. Energy Fuels 2018, 32, 11296-11303. 
(26) Agata, Y.; Yamamoto, H. Determination of Hansen solubility parameters of ionic liquids using double-sphere type of Hansen solubility sphere method. Chem. Phys. 2018, 513, 165-173.

(27) Raynal, M.; Bouteiller, L. Organogel formation rationalized by Hansen solubility parameters. Chem. Commun. 2011, 47, 8271-8273.

(28) Pedersen, T. H.; Sharma, K.; Rosendahl, L. A. Understanding and predicting the solubility of bio-crude oils. Fuel 2020, 271, 117619.

(29) Đukanović, Z.; Glišić, S. B.; Čobanin, V. J.; Nićiforović, M.; Georgiou, C. A.; Orlović, A. M. Hydrotreating of straight-run gas oil blended with FCC naphtha and light cycle oil. Fuel Process. Technol. 2013, 106, 160-165.

(30) Sauvanaud, L.; Mathieu, Y.; Corma, A.; Humphreys, L.; Rowlands, W.; Maschmeyer, T. Co-processing of lignocellulosic biocrude with petroleum gas oils. Appl. Catal., A 2018, 551, 139-145.

(31) Redelius, P. Bitumen Solubility Model Using Hansen Solubility Parameter. Energy Fuels 2004, 18, 1087-1092.

(32) Benjamin, S.; Carr, C.; Walbridge, D. J. Self-stratifying coatings for metallic substrates. Prog. Org. Coat. 1996, 28, 197-207.

(33) Hoffmann, J.; Jensen, C. U.; Rosendahl, L. A. Co-processing potential of HTL bio-crude at petroleum refineries - Part 1: Fractional distillation and characterization. Fuel 2016, 165, 526-535.

(34) Deneyer, A.; Peeters, E.; Renders, T.; Van den Bosch, S.; Van Oeckel, N.; Ennaert, T.; Szarvas, T.; Koranyi, T. I.; Dusselier, M.; Sels, B. F. Direct upstream integration of biogasoline production into current light straight run naphtha petrorefinery processes. Nature Energy 2018, 3, 969-977.

(35) Masson, J.-F.; Polomark, G. M.; Bundalo-Perc, S.; Collins, P. Melting and glass transitions in paraffinic and naphthenic oils. Thermochim. Acta 2006, 440, 132-140.

(36) Wang, W.; Liu, Y.; Liu, Z.; Tian, S. Detailed Chemical Composition of Straight-Run Vacuum Gas Oil and Its Distillates as a Function of the Atmospheric Equivalent Boiling Point. Energy Fuels 2016, 30, 968-974.

(37) Djokic, M. R.; Dijkmans, T.; Yildiz, G.; Prins, W.; Van Geem, K. M. Quantitative analysis of crude and stabilized bio-oils by comprehensive two-dimensional gas chromatography. J. Chromatogr. A 2012, 1257, 131-140.

(38) van Beek, F. T.; Edam, R.; Pirok, B. W. J.; Genuit, W. J. L.; Schoenmakers, P. J. Comprehensive two-dimensional liquid chromatography of heavy oil. J. Chromatogr. A 2018, 1564, 110-119.

(39) Hung, A. M.; Mousavi, M.; Pahlavan, F.; Fini, E. H. Intermolecular Interactions of Isolated Bio-Oil Compounds and Their Effect on Bitumen Interfaces. ACS Sustainable Chem. Eng. 2017, 5, 7920-7931.

(40) Negahdar, L.; Gonzalez-Quiroga, A.; Otyuskaya, D.; Toraman, H. E.; Liu, L.; Jastrzebski, J. T. B. H.; Van Geem, K. M.; Marin, G. B.; Thybaut, J. W.; Weckhuysen, B. M. Characterization and Comparison of Fast Pyrolysis Bio-oils from Pinewood, Rapeseed Cake, and Wheat Straw Using ${ }^{13} \mathrm{C}$ NMR and Comprehensive GC $\times$ GC. ACS Sustainable Chem. Eng. 2016, 4, 4974-4985.

(41) Kass, M. D.; Janke, C. J.; Connatser, R. M.; Lewis, S. A.; Keiser, J. R., Sr.; Gaston, K. Compatibility Assessment of Fuel System Infrastructure Plastics with Bio-oil and Diesel Fuel. Energy Fuels 2018, $32,542-553$.

(42) Burris, D. R.; Macintyre, W. G. Water solubility behavior of binary hydrocarbon mixtures. Environ. Toxicol. Chem. 1985, 4, 371377.

(43) Szabó, G.; Romhányi, V.; Kun, D.; Renner, K.; Pukánszky, B. Competitive Interactions in Aromatic Polymer/Lignosulfonate Blends. ACS Sustainable Chem. Eng. 2017, 5, 410-419.

(44) Gautrot, J. E.; Hodge, P.; Cupertino, D.; Helliwell, M. Experimental evidence for carbonyl $-\pi$ electron cloud interactions. New J. Chem. 2006, 30, 1801-1807.

(45) Sharma, K.; Pedersen, T. H.; Rosendahl, L. A. Delivery of 50$60 \mathrm{~kg}$ of HTL bio-liquid for baseline upgrading activities (M12). Deliverable D2.11 of the European Union's HORIZON 2020 project "4REFINERY"; Grant Agreement No. 727531; 2018.
(46) Abbott, S.; Hansen, C. M.; Yamamoto, H. Hansen Solubility Parameters in Practice. https://www.hansen218solubility.com/HSPiP/

(47) ASTM International. D2892 standard test method for distillation of crude petroleum (15-theoretical plate column); 2005; DOI: 10.1520/ D2892-05.

(48) ASTM International. D5236 standard test method for distillation of heavy hydrocarbon mixtures (vacuum potstill method); 1999; DOI: $10.1520 / D 5236-18$ A. 